\title{
A SOCIEDADE BRASILEIRA EM MOVIMENTO: vozes das ruas e seus ecos políticos e sociais
}

\author{
Maria da Glória Gohn*
}

\begin{abstract}
O texto tem por objetivo analisar as especificidades e novidades presentes nas manifestações de Junho de 2013 no Brasil, por meio de algumas questões-chave, a saber: como eram compostas, as identidades, o pertencimento, os valores e as ideologias que tinham; o que demandavam, como se articulavam no plano interno e internacional; quais as relações com estado, partidos e outros movimentos sociais; como surge a violência nas manifestações; qual a concepção de democracia dos ativistas; como foi pautada a ideia de reformas etc. Uma questão central é colocada: por que uma grande massa da população aderiu aos protestos em Junho de 2013? Inicialmente, faz-se a reconstrução dos momentos iniciais das manifestações, especialmente em São Paulo, analisando-as a seguir segundo seus impactos na sociedade e na política. As fontes dos dados advêm de arquivos sistematizados via diferentes mídias, entrevistas, pesquisas de opinião pública, e publicações recentes.

PaLAVRAS-CHAvE: Manifestações. Protestos. Movimentos sociais. Mobilização da sociedade civil. Ativismo sociopolítico.
\end{abstract}

Em Junho de 2013, ocorreu, em 12 capitais brasileiras e em várias outras cidades de médio porte, uma onda de manifestações populares que reuniu mais de um milhão de pessoas, com similares em apenas três momentos da história do país: em 1992, no impeachment do ex-presidente Collor de Melo; em 1984, no movimento Diretas Já, no período do regime militar, na luta pelo retorno à democracia; e nos anos de 1960, nas greves e paralizações pré-golpe militar de 1964, e nas passeatas estudantis de 68. Os protestos rapidamente se espalharam e se transformaram em revolta popular de massa. Os movimentos foram denominados pela mídia e outros como "manifestações". De fato, eles foram, na maioria das vezes, manifestações que expressam estados de indignação face à conjuntura política nacional. As mobilizações adquiriram, nesses eventos, um caráter de movimento de massa, de protesto, de revolta coletiva,

*Doutora em Ciência Política. Professor titular da Faculdade de Educação da Universidade Estadual de Campinas (UNICAMP).

Rua Bertrand Russel 801. Barão Geraldo. Caixa-postal: 6120. Cep: 13083-970. Campinas - São Paulo - Brasil. mgohn@uol.com.br aglutinando a indignação de diferentes classes e camadas sociais, predominando a classe média propriamente dita, e diferentes faixas etárias, destacando-se os jovens. Sabe-se que elas foram desencadeadas em São Paulo por coletivos organizados, com o predomínio do Movimento Passe Livre (MPL), a partir de uma demanda pontual contra o aumento da tarifa dos transportes coletivos. Quando o 'povo' viu, na TV e jornais, jovens sendo espancados por lutarem por bandeiras que eram também suas, como a mobilidade urbana, ele também saiu às ruas. $\mathrm{O}$ crescimento das manifestações levou à ampliação das demandas com um foco central: a má qualidade dos serviços públicos, especialmente transportes, saúde, educação e segurança pública. As manifestações fazem parte de uma nova forma de movimento social, que se caracteriza por participação de uma maioria de jovens escolarizados, predominância de camadas médias, conexão por e em redes digitais, organização horizontal e de forma autônoma, e crítica às formas tradicionais da política da atualidade - especialmente os partidos e os sindicatos. As convocações para os atos foram feitas através das re- 
des sociais, e a grande mídia contribuiu para a adesão da população ao noticiar a agenda, os locais e a hora das manifestações. Há uma estética particular nas manifestações: em cima da demanda-foco, sem carros de som o batuque ou as palmas são utilizados no percurso das marchas. Os jovens organizadores das chamadas para as manifestações atuam em coletivos organizados na última década. Muitos dos jovens que respondem às convocações e vão às manifestações estão em fase de batismo na política. Os coletivos inspiram-se em variadas fontes, segundo o grupo de pertencimento de cada um. Como rejeitam lideranças verticalizadas, centralizadoras, também não há hegemonia de apenas uma ideologia ou utopia. O que os motiva é um sentimento de descontentamento, desencantamento e indignação contra a conjuntura ético-política de dirigentes e representantes civis eleitos nas estruturas de poder estatal, assim como as prioridades nas obras e ações selecionadas e seus efeitos na sociedade. O movimento acontece "em se fazendo" e não via grandes planos de organizações com coordenações verticalizadas. Há processos de subjetivação na construção dos sujeitos em ação. Cada um leva seu cartaz em cartolina; uma nova mensagem pode gerar uma decisão tomada no calor da hora, em cima da demanda-foco; sem carros de som, o batuque ou as palmas são utilizados no percurso das marchas, como já mencionado. Na estética individual, predomina o preto, máscaras de gás ou outras (como a de Guy Fawkes, do Anonymous), e eventuais piercings. Os ativistas também constroem seu "capital militante" (Bourgeois, 2008) antes, durante e depois das ações.

Os ativistas dos movimentos sociais deste novo século foram e continuam a ser alvos de ações violentas por parte da repressão policial. Conectam-se às redes de apoio internacional, e a solidariedade entre eles é um valor e um princípio. São laboratórios de experimentações de novas formas de operar a política. Dirigem suas reivindicações a personagens específicos da cena público-política de cada país.

Para compreender essa onda de mobilizações, além de identificar as especificidades e dife- renças dos jovens em ação, há uma questão significativa. Por que uma grande massa da população aderiu aos protestos? Ou seja: Que sentido e significado esses jovens atribuíram aos acontecimentos para transformá-los em movimento de massa com ampla legitimidade?

Quais as fontes de motivação desses movimentos? Que ideologias os inspiram? Inspiram-se em variadas fontes, segundo o grupo de pertencimento de cada um. Como rejeitam lideranças verticalizadas, centralizadoras, não há hegemonia de apenas uma ideologia, utopia ou esperança que os motive. Alguns retiram, da esquerda, ensinamentos sobre a luta contra o capital e as formas de controle e dominação do capitalismo contemporâneo, na busca da emancipação. Do anarquismo e do socialismo libertário, grupos ressuscitam e renovam leituras sobre a solidariedade, a liberdade dos indivíduos, a autogestão, e a esquecida fraternidade, retomada nas ações de enfrentamento à repressão policial. Há também um novo humanismo na ação de alguns, expresso em visões holísticas e comunitaristas, que critica a sociedade de consumo, o egoísmo, a violência cotidiana-real ou monitorada pelo medo nas manchetes diárias sobre assaltos, roubos, mortes etc., a destruição que o consumo de drogas está causando na juventude e outros. Busca-se reumanizar os indivíduos, promover a paz, combater a violência. Muitos não têm formação alguma, estão aprendendo na luta do dia a dia, formatando seus valores conforme o calor da hora. D. Cohn-Bendit (2013) ${ }^{1}$ observou, a respeito das manifestações no Brasil: "Nos anos 60 prevalecia a defesa dos ideais, socialismo, anarquismo, alguns lutavam em nome de Cuba, da China. Hoje não há a questão ideológica. Isso ébom: lutar por escola melhor, transporte melhor".

Que reivindicações sintetizam as palavras de ordem das atuais manifestações? Quais são os grandes temas que mobilizam esses jovens? No início, sabemos que o foco esteve nos transportes públicos, que, no Brasil, constituem o transporte coletivo, por-

${ }^{1}$ D. Cohn-Bendit. "Violência em protesto reduz influencia, diz líder de Maio de 68" entrevista à Fabio Brisolla. Folha de São Paulo, 06 nov. 2013, p. C7. 
que o caráter público se esvai com as concessões às empresas privadas, na sua operacionalidade. Depois, o leque de demandas ampliou-se para outros serviços públicos (saúde e educação). Com a adesão de multidões às manifestações, as demandas ampliaramse mais ainda, e o alvo passou a ser "contra tudo", além da denúncia sobre a violência da polícia. Os slogans dos cartazes, a maioria deles escritos à mão, rudimentares, são emblemáticos para ilustrar essa questão: "Nossos sonhos valem mais que 0,20”; "Democracia já", "Desculpem o transtorno, mas estamos construindo outro Brasil", ou "Desculpem o transtorno, estamos mudando o país", "A Juventude acordou”, "O povo não deve temer o governo, o governo deve temer o povo", “O Gigante acordou”, “Ou para a roubalheira, ou paramos o Brasil”, etc. Observa-se que há doses fortes de conteúdo moral e ético nas enunciações. Alguns analistas viram nacionalismo na frase "O gigante acordou" (li essa frase também em Istambul, onde me encontrava ao final de Junho de 2013, em manifestação dos turcos em apoio às manifestações no Brasil); outros afirmaram que ele (o país) nunca esteve dormindo. O fato é que frases proferidas expressam um grande recado: não estamos satisfeitos, não queremos esse modelo de desenvolvimento. As frases também expressavam ideias: "O povo unido não precisa de partido", "Parem de falar que é pela passagem. É por um Brasil melhor”. No caso de São Paulo, um ativista do MPL deixou claro "Nós queremos um novo plano diretor e maior mobilidade na cidade". Portanto, aqueles que afirmam não ter o movimento metas, propostas, projetos, estão sendo cegos e surdos, porque suas demandas estão na base de outro modelo de desenvolvimento, voltadas para a escolha de outras prioridades nas políticas públicas, e para outros parâmetros éticos dos os políticos que ocupam cargos públicos.

\section{A VIOLÊNCIA E A REPRESSÃO POLICIAL}

A questão da violência entrou na pauta dos movimentos e manifestações no Brasil em 2013 de forma multifacetada e deve ser examinada para a análise das manifestações de 2013. Esclareça-se que a violência sempre esteve presente na história dos movimentos sociais no Brasil, quer na forma como muitos foram tratados pelas forças policiais, quer na forma de resistência pelos próprios movimentos, especialmente na área rural, onde as relações sociais historicamente têm sido pautadas por formas de violência. A novidade, em 2013, é que a violência entra em cena nas manifestações de rua por duas vias: a policial, várias vezes de forma brutal, tratando os manifestantes tal como enfrentam uma ocupação de marginais em uma favela, com todo aparato da repressão; e a violência no comportamento de alas dos manifestantes, apresentada como violência simbólica, como tática do movimento (Black Blocs), uma ala pequena e ativa no conjunto mais geral dos manifestantes. Embora os Black Blocs não se denominem movimento, mas tática, sua visibilidade performática domina a cena quando eles se manifestam. Nas manifestações de 2013, pode-se indagar se ela ressurge como nova forma de luta social ou internacionalização de formas de protesto. O fato novo é a violência ser apresentada e justificada por essas alas dos manifestantes como forma predominante da ação no protesto, e esse fato reforça a hipótese de mudança na composição e no caráter dos movimentos nas ruas. A violência performática como norma de conduta é um registro de formas de movimentos de protestos internacionais deste novo século. As manifestações iniciadas em Junho, em São Paulo, foram caracterizadas, inicialmente, na mídia e por muitos políticos, como atos de "vândalos". Uma manifestante, revoltada com esse tratamento, saiu no dia 13 de Junho com um cartaz: "Não sou vândalo, mídia”. Nesse dia, na quarta manifestação do movimento em São Paulo, a polícia tratou a todos como inimigos, e houve centenas de feridos, muitas prisões e muita indignação. Esse dia marcou a virada do olhar da sociedade, que passou a apoiar o movimento e ir às ruas para se manifestar também. A partir de então, pode-se observar melhor o que foi denominado como as "tribos" que compunham o núcleo permanente dos manifestantes. Em São Paulo, participaram das manifestações, junto com o MPL, integrantes de 
partidos de esquerda: PSOL, PSTU, PCO e alguns militantes do $\mathrm{PT}^{2}$ Todas as bandeiras partidárias foram rejeitadas nas manifestações, gerando, inclusive, tumultos entre os que insistiram em desfraldá-las. Grupos anarquistas (Black Bloc, Anonymous e Kaos) estiveram presentes, com máscaras ou não. Houve também a presença de alguns punks. Os novíssimos movimentos sociais dos indignados das praças, ruas e avenidas, em várias partes do mundo, contam com a presença de grupos anarquistas, e alguns reagem com violência à violência policial, em dadas circunstâncias. Eles são parte das novas formas de movimentos. Representam a "resistência" - expressão usada nos países da Primavera Árabe e outros para indicar os que não desistem, os que enfrentam e afrontam o poder constituído. Muitos são presos, feridos ou mortos, pois são alvos prediletos das ações de repressão da polícia. Quando ocorrem ações violentas, os confrontos são desiguais, porque a maioria dos manifestantes porta apenas equipamento de autoproteção - máscaras, água, vinagre, bolinhas de gude para atrapalhar a cavalaria etc. $\mathrm{O}$ fato de os movimentos serem constituídos por coletivos diversificados e diferenciados causa problemas internos quando um dos grupos implementa ações próprias, ou quer se destacar mostrando suas bandeiras partidárias, por exemplo, ou usando a violência, depredando bens públicos e privados. Acrescentem-se às dificuldades nas ações dos coletivos fatos como os ocorridos em algumas manifestações, quando grupos de populares aproveitaram a confusão e saquearam lojas e edifícios públicos.

A sociedade, os movimentos sociais novos e antigos e as autoridades não sabem como lidar com essa nova forma de expressão do protesto social que destrói, não tem nome, não se assume como grupo ou movimento.

Para Esther Solano, professora da Universidade Federal de São Paulo (UNIFESP) que desenvolve pesquisa sobre os Black Blocs, a violência

2 São siglas dos partidos políticos: PSOL - Partido Socialismo e Liberdade; PSTU - Partido Socialista dos Trabalhadores Unificado; PCO - Partido da Causa Operária; e PT - Partido dos Trabalhadores. funciona para eles como uma forma de se expressar socialmente. Ela os caracteriza como de "classe média baixa, a maioria trabalha, alguns são formados ou estão se formando em universidades particulares”. Esther Solano e Rafael Alcadipani (2013, p.C7) ainda afirmam:

Muitos Black Blocs já me disseram que, para eles, a violência é a única forma de expressão pela qual, de fato, são ouvidos. É difícil contestar esse raciocínio. Se a imprensa só dá voz às formas de protestos violentos, se o governo reage com mais força diante do fator violência, como impedir que a violência se torne uma forma de protesto generalizada? A violência como forma de protesto não estaria sendo legitimada e reforçada por toda a sociedade que joga o jogo da espetacularização? ${ }^{3}$

A prática sistemática da violência nas diferentes manifestações ocorridas ao longo de 2013, após Junho de 2013, ofuscou a legitimidade das ações, afastou as grandes massas das manifestações e contribuiu para o isolamento e segmentação dos ativistas. Vários analistas concordam com essas ponderações. D. Cohn-Bendit, na entrevista acima citada, disse "O emprego da violência é algo que reduz a influência de uma manifestação sobre a sociedade". O poder das ruas, construído em Junho, passou a ser desconstruído, pois, como alerta H Arendt, poder e violência não se confundem: a violência não cria poder, o destrói.

\section{A QUESTÃO DA IDENTIDADE DAS MANIFES- TAÇÕES}

No exterior, muitos dos protestos dos indignados têm sido conhecidos pela data que eles iniciaram suas ações coletivas. No caso do Occupy, são nominados como movimento. No Brasil, eles têm sido nominados pela mídia como "manifestações". Os próprios manifestantes de Junho de 2013, no Brasil ,autodenominam suas ações como "atos".

\footnotetext{
A matéria intitulada "Violência 'black bloc' visa chamar atenção de um Estado ausente" foi publicada na Folha de São Paulo em 17/10/2013, C7. Uma entrevista de Esther Solano também foi citada por Bruno P Manso, sob o título "Violência em atos ofusca movimentos pacíficos" no jornal Estado de São Paulo em 3/11/2013, p. A27.
} 
Analistas têm se referido a eles como "jornadas". Eu considero que, em Junho, houve algo mais que jornadas ou atos. Houve "protestos". E causa estranhamento a ausência da palavra movimento nas referências, assim como não se usa mais o termo "marcha", comum nas ações dos sem-terra e outros específicos, como a Marcha da Maconha, a Marcha das Vadias etc. Alguns analistas nominaramnos como “ondas”. Essa questão é importante, porque remete à identidade do movimento, e é o nome que as manifestações adotam ou ganham pelo mundo. Desde logo, registre-se: encontrar eixos identitários é possível, mas unidade é impossível, pois são blocos diferenciados internamente. A esse respeito, assinala Rodrigo Guimarães Nunes (2013):

Há alguns anos, Alain Badiou se perguntava sobre o sentido de maio de 68 ser conhecido na França como "eventos de maio": "se dizemos que um evento tem 'evento' por nome, isto quer dizer que ainda não encontramos seu nome”. [1] Talvez para situá-los confortavelmente no passado, alguns começam a falar no Brasil dos "eventos de junho". O fato é que nenhum nome (Revolta do Vinagre, Revolta da Tarifa, Inverno Brasileiro...) pegou; ao contrário da Primavera Árabe, do Occupy Wall Street, do 15M espanhol, do YoSoy132 mexicano e do Diren Gezi turco, o movimento brasileiro, se assim se pode chamá-lo, não tem nome. Qual é o nome de uma legião, quando legião é seu nome? Não é apenas questão de reconhecer uma identidade (“quem é essa gente?”), mas de identificar uma vontade (“o que eles querem?”).

O termo manifestação foi adotado também neste texto, porque ele já entrou no vocabulário e no imaginário da população para relatar os acontecimentos de Junho de 2013. Entretanto, eu considero as manifestações como parte de um movimento social de protesto e não como um evento separado, ad hoc, como se não fosse um movimento social propriamente dito. Sei que a discussão é longa, remete à contínua questão que sempre retorna: o que é um movimento social? Em outras obras, já trabalhei a questão, apontando que não há uma definição unívoca, mas muitas. A pluralidade decorre dos diferentes paradigmas de interpretação. Na nossa interpretação, as manifestações são movimentos que construíram significados novos para as lutas sociais (essa sim, uma ca- tegoria mais ampla). E construíram esses novos significados porque novos sujeitos entraram em cena, com práticas diferenciadas, valores, formas de ação e procedimentos discursivos (bastante modernos, quando on line, antigos e rudimentares, quando em cartazes).

\section{A QUESTÃO DA DEMOCRACIA E AS MANI- FESTAÇÕES}

Uma das questões profundas que está em causa nas manifestações de Junho é a discussão da democracia. Esse contexto denota que a democracia representativa está em crise, e a democracia direta é um ideal viável apenas em pequenos grupos ou comunidades. A democracia deliberativa poderia unir as duas anteriores, mas ainda é um modelo frágil, que padece de arranjos clientelistas nos poucos casos onde ocorre. Mas, apesar de a democracia estar em crise, há certo consenso de que ela é necessária. Sendo assim, podem-se buscar, nas atuais manifestações, os indícios de novas formas de organização política, nos marcos de uma nova forma - a democracia analógica, aquela que tenta dialogar com a geração digital, que poderá combinar a democracia representativa com a democracia direta via on line. Os novos movimentos sociais dos jovens são movimentos sociais e só poderão ser considerados como em transição para movimentos políticos desde que se entenda a política de forma diferente da atualidade. A política como arte de construção do bem comum. O movimento expressa uma profunda falta de confiança em toda forma de política e na categoria de políticos. Por isso, sua mensagem foi respondida por milhares que se uniram a eles, indo às ruas. Eles querem outro país, onde a ética e a política andem juntas. Querem uma revolução na forma de operar a política, e não uma reforma ou remendo no que existe. Não confiam na política atual e nem nos políticos. Negam a política atual, e isso também é uma forma de propor outra coisa. A exemplo do MPL, que se declara apartidário, mas não antipartidário, eles querem renovar a política e o tipo de partidos e 
políticos atuais. Por isso o tema de uma reforma política inicialmente não os atraiu - a reforma seria feita pelos políticos que estão aí, os que eles estão contestando. Não se sentem representados no quadro político institucional existente. Eles não têm canais de expressão. Com isso, detecta-se também uma crise de representação social desses grupos e uma crise de legitimidade das instituições públicas. A linguagem política dos manifestantes é outra. Seus códigos não se enquadram em planilhas, organogramas, planejamentos, siglas de planos e projetos.

Querem mudanças na política via atuação diferenciada do Estado no atendimento à sociedade. Não negam o Estado, mas querem um Estado mais eficiente. Apresentam-se como apartidários, mas não antipartidários.

Resta, portanto, buscar, nos atuais movimentos, os indícios de novas formas de organização política, nos marcos da democracia. Seriam eles movimentos sociais em transição para movimentos políticos, que construiriam novas formas de representação? Talvez sim, desde que se entenda a política de forma diferente da atualidade. A política como arte da negociação para a construção do bem comum. Aqueles que decretaram a morte das utopias precisam rever suas ideias. A nova geração de jovens que se organizou e foi às ruas em Junho de 2013 não se identifica com as formas organizativas existentes, e eles estão atentos ao modelo de sociedade em que vivem. Muito consumo, mas qualidade de vida sofrível.

Não se pode esquecer a capacidade deaprendizagem e a resistência dos ativistas. Sabem o que não querem, ebuscam definir oquequerem nos parâmetros dos valores em que acreditam. Os coletivos e as manifestações são grandes laboratórios de experimentação sobre novas formas de operar a política.

\section{AS MANIFESTAÇÕES E A QUESTÃO DAS REFORMAS}

O espanto e susto que as manifestações de Junho de 2013 provocaram no governo, na mídia e em membros da sociedade, que não estavam atentos aos sinais emitidos há mais de dois anos, logo partiram para recuperar o terreno e fazer propostas de reformas. Mas que reformas? "Uma reforma que amplie as possibilidades e oportunidades de participação, e seja capaz de incluir e processar os projetos de transformação que sujeitos políticos historicamente excluídos dos espaços de poder trazem para o cenário político. Foi essa a principal lição que as manifestações de junho nos colocaram.” (Caccia-Bava, 2013, p.1) completa:

A democratização da gestão tornou-se um imperativo para legitimar e revigorar nossas instituições ainda chamadas de democráticas. Ou essas velhas instituições se abrem para uma reforma política, ou as mobilizações não vão parar. Também está em xeque toda a "arquitetura da participação", dos conselhos de políticas públicas e de direitos, assim como das conferências sobre políticas públicas. Consideradas por muitos um avanço na democratização da gestão, se elas não ouvirem as vozes das ruas, se não abrirem para receber novos atores, renovarem as representações e as agendas, criarem novas regras de funcionamento, podem estar chegando ao seu fim como canal de diálogo e negociação com a sociedade.

Reformas políticas estiveram na pauta das sugestões. Perry Anderson (2013), em entrevista ao Estado de São Paulo afirmou: “[...] a chave para a reforma política precisa ser uma transformação do sistema político, cuja involução para uma ordem decadente e ensimesmada, afastada da vida popular do país, é agora amplamente reconhecida".

Vários analistas destacaram, logo após as manifestações de Junho, que faltava a esses movimentos definições estratégicas, programáticas e teóricas, alertando para a fragilidade organizatória do movimento, a não definição de rumos, e o perigo de ser apropriado por forças conservadoras da direita, como já ocorreu em outros momentos históricos de tensão social (Ali et al., 2012; Chaui, 2013). Destacaram também o cenário sombrio: crise econômica e desemprego. Observam-se quatro pontos básicos nessas análises. Em primeiro lugar, muitos diagnosticaram situações típicas dos países antes tidos como "desenvolvidos" ou do primeiro mundo. Entretanto, a crise e a situação 
das classes e lutas sociais, em países da América Latina como o Brasil ou a Bolívia ou a Venezuela, na última década, são bastante diferentes das crises dos países europeus ou dos Estados Unidos a partir de 2008. Em segundo lugar, deve-se observar também que muitos dos que não encontraram programas ou estratégias claras nas manifestações o fazem sob a ótica teórica da esquerda, da luta de classes etc.

Entretanto, vários desses movimentos se inspiram mais nos ideais dos anarquistas do que nos da esquerda tradicional. É interessante resgatar alguns dos princípios do anarquismo do século XIX, na figura de Proudhon e Kropotkin, por exemplo, para observar as similaridades com ideias e ideais contemporâneos. A ideia de anarquia surge a partir do desejo de liberdade, igualdade, justiça e independência, de um governo que não é governo. A reorganização de sociedade deveria ocorrer através de associações livres de contato. As mudanças econômicas deveriam ter primazia em relação às políticas. As "Sociedades de Ajuda Mútua” seriam os principais meios de realizar a mudança social sem violência, dado seu caráter. Seu objetivo deveria ser a ação e a cooperação econômica, e não a associação para a propaganda política. O sistema que caracterizaria essa nova sociedade foi denominado por Proudhon de mutualista. Além do mutualismo, outras correntes do anarquismo que adotam a violência como forma de ação também estão presentes nas atuais manifestações. Sabe-se que o anarquismo e o socialismo libertário têm várias correntes.

Apesar da intensa participação dos jovens nas manifestações de Junho de 2013, seus impactos na sociedade têm tido visibilidade contraditória. Ora são heróis, glorificados como a boa nova, o futuro, ora criticados violentamente, descaracterizados como vândalos, ingênuos, portadores do "pensamento mágico", tendo uma relação mágica com a sociedade (Chaú, 2013), sem mediação política, sem direção, liderança etc. O grande problema dessas visões e abordagens é o fato de considerarem os jovens e as manifestações como um todo, um bloco homogêneo. Não se consideram as diferenças internas, a diversidade de perfis de seus componentes, os matizes ideológicos. Fazem uma leitura com os óculos de uma dada abordagem e, como não encontram os elementos dessa abordagem nas manifestações, descaracterizam-nas. Não querem ver ou não aceitam que elas têm outros pressupostos, outros referenciais. Por exemplo, podem-se observar, nas diferentes manifestações da atualidade, as influências antes citadas da Internacional Situacionista dos anos de 1960 que, entre outras coisas, tinha uma proposta de criar situações para que novos fatos e mudanças viessem a ocorrer (vide Guy Debord, Manifesto da Internacional Situacionista).

\section{MANIFESTAÇÕES DE JUNHO E ATIVISMO INTERNACIONAL}

O campo de luta dos atuais movimentos de protesto no Brasil em 2013 é diferenciado, quer se trate dos Occupy nos Estados Unidos, dos Indignados da Europa, ou dos árabes e sua primavera de 2011. Confundi-los ou trata-los sem distinções significa ignorar a conjuntura política de cada país: uns têm a democracia como regra do jogo político; outros estão lutando contra o autoritarismo, buscando a democracia. De toda forma, o horizonte dos jovens rebeldes, na atualidade, situa-se no plano democrático. O igualitarismo democrático radical pode ser visto como o cerne da bandeira de alguns desses movimentos, como os "Occupy” (Ali et al, 2012, p. 29). Esse igualitarismo expressa-se em bandeiras genéricas. Alguns se fixam em certos pontos, tais como a necessidade de subir impostos dos mais ricos, ou regulamentar os bancos, ou outras medidas pontuais.

O fato concreto é que, no exterior, as manifestações de jovens em 2011, via atos públicos, ocupações e marchas, chegaram a derrubar ditaduras, como na Primavera Árabe, em 2011 (ainda que tenha ocorrido retrocessos, como no Egito em 2013); abalaram governos europeus desestabilizados por crises econômicas e ondas de desemprego, como o Movimento dos Indignados, na Espanha; ou ainda questionaram o modelo econômico-financeiro 
vigente, como o Movimento Occupy Wall Street, iniciado em Nova York e que se espalhou pelo mundo. Os manifestantes não têm utopias grandiosas do passado, mas eles têm novas, as do momento presente. A esse respeito, Tarik Ali relembra O. Wilde: "Um mapa do mundo que não inclua Utopia não merece ser olhado.” (Ali et al, 2012, p. 65).

Além de ocorrerem em tempo histórico comum, de terem, nas redes e mídias sociais, um poderoso aliado e contarem com grande participação de jovens, há grandes diferenças entre as três formas mencionadas. Por isso, concordamos com a crítica feita por Contardo Calligaris (2011, p. E14), que disse:

[...] esses movimentos e manifestações têm uma só coisa em comum: todos juntos, eles permitem uma espécie de 'pauta projetiva'. Ou seja, eles não têm pauta comum (e, às vezes, não têm pauta alguma), mas, uma vez reunidos, constituem um conjunto suficientemente incerto para que nós, observadores, possamos lhes atribuir uma pauta que é da gente.

Para Castells (2013b, p. 3), movimentos como o que propôs a criação coletiva da constituição da Islândia, os Indignados na Espanha, o Occupy Wall Street nos Estados Unidos, a Primavera Árabe e o grupo Anonymous são parte de um mesmo movimento, coletivo e global, que não é político, e sim social. "São estes movimentos, sociais e não polí ticos, que realmente mudam a história, pois realizam uma transformação cultural, que está na base de qualquer transformação de poder". Esses movimentos começam na internet, mas não são essencialmente digitais. "Eles só tornam-se visíveis e passam a existir de fato quando tomam as ruas", explicou, reforçando que eles acontecem há apenas cinco anos e que eles não têm lideranças, repudiam a violência e, embora não tenham objetivo definido, encontrem coincidências e semelhanças ao indignar-se.

São movimentos emocionais e que se unem pela recuperação de uma dignidade que se perdeu. Às vezes eles começam pequenos e parecem que se mobilizam por pouca coisa, mas que funcionam como apenas uma gota a mais em uma indignação que existe em todos os setores sociais, que as pessoas não aguentam mais. (Castells, 2013b, p.4)

Realçando que isso pode ser motivado pela construção de um shopping para turistas, na praça Taksim na Turquia, ou o aumento de centavos nas passagens de ônibus, em São Paulo. "Centenas de milhões de pessoas já participaram destes movimentos". Continua afirmando que:

[...] são movimentos que podem ter saído das ruas, mas não desapareceram. Eles continuam online. Quando vem a repressão física, eles se retiram das ruas, rediscutem online. Não têm líderes nem programa, mas têm a capacidade de resistir e de renascer a qualquer momento. Isso só acontece porque há a capacidade de autocomunicação de massa que os permitiu existir. (Castells, 2013b, p.4)

E conclui: "A palavra 'dignidade’ aparece em todos os países, em todos estes movimentos, em diferentes países e culturas. Eles não têm uma reivindicação concreta, mas querem o reconhecimento da própria dignidade, pois as pessoas não se veem reconhecidas como pessoas ou cidadãos". Castells (2013b) reforçou que as semelhanças entre movimentos que partem de causas tão distintas apenas enfatizam seu papel no século 21 - e compara o que está acontecendo nos últimos anos com o que aconteceu nos últimos 40 anos no que diz respeito às mulheres, sem se referir a um autor, ideologia ou movimento feminista específico. "Foi um movimento coletivo, em que todas as mulheres do mundo decidiram abandonar o papel de sujeitadas para assumirem o papel de sujeitas da história”, reforçou, lembrando os avanços da ascensão do papel da mulher na sociedade na última metade de século, principalmente em comparação a milênios de história. E, segundo ele, isso está acontecendo de novo, nesta nova forma de manifestação social - que demanda mudanças culturais mais do que políticas.

Um ponto unânime para a maioria dos analistas: esses movimentos têm conseguido “... alterar o discurso mundial, levando-o para longe dos mantras ideológicos do neoliberalismo, para temas como a desigualdade, injustiça e descolonização." (Ali et al, 2012, p.75). 


\section{CONSIDERAÇÕES FINAIS}

Neste texto, buscamos analisar as manifestações de Junho de 2013 no Brasil por meio de indagações que focalizam eixos-chave nos acontecimentos, a saber: como eram compostas; as identidades, os pertencimentos, os valores e as ideologias que tinham; o que demandavam; como se articulavam no plano interno e internacional; quais as relações com Estado, partidos e outros movimentos sociais; a questão da violência presente nas manifestações; qual a concepção de democracia dos ativistas; como foi pautada a ideia de reformas etc. Em suma, tratase da "surpresa" que as manifestações representaram para parcela significativa da sociedade, que logo aderiu a elas, assim como a surpresa do governo. Em relação a esse último, destacam-se, especialmente, os impactos e reações no governo federal, o qual fez, nos últimos anos, grandes esforços e investimentos na construção de uma institucionalidade da participação democrática para a inclusão de representantes da sociedade civil organizada nos movimentos e associações, tidas até então como clássicas (sindicatos) ou representativas dos novos movimentos sociais (organizados por questões étnicas, de gênero, geracional, cooperativas de trabalho etc.). O texto buscou decodificar, no processo, o comportamento dos atores em cena, especialmente os denominados "ativistas" (membros de novos coletivos), indagando o que eles representavam em termos da sociedade civil (não organizada, mas participante naquele momento), e a relação ou reação do Estado e dos órgãos policiais aos movimentos.

As "vozes" que ecoaram nas ruas em Junho não negavam o Estado, mas reivindicavam um Estado menos dependente dos bancos, de multinacionais, de empresários etc. Um Estado com pauta social efetiva, e não apenas focado nas metas e índices de crescimento e oferta de bens. Clamaram por mais cidadania social. A cidadania, vigente no país, nos últimos anos, melhorou os índices de pobreza e promoveu a inclusão social, mas reduziu o cidadão a um consumidor. Reduziu a questão dos direitos a uma pauta de consumo. Ou seja, a questão central colocada no início - Por que uma grande massa da população aderiu aos protestos em Junho de 2013? - tem múltiplas respostas que podem ser resumidas num grande foco: aderiram porque se identificaram com os manifestantes da primeira hora. Aderiram porque estavam atentos ao cenário nacional e se sentiam não representados ("não nos representam" foi o dizer de um dos cartazes bastante comum), sem canais de expressão e, nesses momentos, o protesto explode. Sentiam-se detentores de direitos no papel, na lei, mas não na prática (tais como: ser bem atendido, na hora que necessita do sistema público de saúde como um cidadão, segundo preconiza a lei; ter uma escola com ensino de qualidade etc.). Com as manifestações, essescidadãos-consumidores constituíram-seem sujeitos de direitos no espaço público, como forma de expressar suas exigências e sua existência.

A grande mídia contribuiu de diversas formas com as manifestações: ajudando na divulgação de data, horário e local dos atos; nas tintas sobre "os vândalos", contribuindo para a criminalização dos protestos como um todo; espetacularizando como a coisa mais importante do dia; e noticiando pautas, divulgando fotos, fazendo enquetes, revelando quem eram os manifestantes, muitas vezes via a identificação dos que eram presos.

Na nossa interpretação, as manifestações são movimentos que construíram significados novos para as lutas sociais. Certamente que seus protestos vão além do ativismo digital, que é um meio para um fim: a manifestação propriamente dita. Há múltiplos processos de subjetivação na construção dos sujeitos em ação, o que dificulta prever seus desdobramentos - os acontecimentos, no calor da hora, provocam reações que geram novas frentes da ação coletiva. A composição dessas novas frentes é complexa, diversificada, com múltiplos atores, propostas e concepções sobre a política, a sociedade, o governo etc. Como essas diferenças poderão ser resolvidas, sem líderes-chave (motivo de dificuldade também no diálogo ou negociação com os poderes constituídos), sem canais de intermediação validados como legítimos pelos ativistas e pelos órgãos públicos responsáveis (desde que os canais tradicionais de participação nos partidos, sindicatos e outras instâncias 
associativas foram negados)? Tudo isso é uma incógnita. Um enigma a decifrar, pois é impossível manter mobilizações de massa por muito tempo. Mas as raízes da revolta e dos protestos continuam prestes a explodir a qualquer momento.

Recebido para publicação em 23 de novembro de 2013 Aceito em 23 de março de 2014

\section{REFERÊNCIAS}

ALI, Tariq: ALVES, Giovanni: DAVIS, Mike; HARVEY, David; SADER, Emir; SAFATLE, Vladimir; PESCHANSKI, João Alexandre; •I・EK, Slavoj; TELES, Edson, WALLERSTEIN, Immanuel. Occupy. Movimentos de protestos que tomaram as ruas. São Paulo: Boitempo, 2012.

ALVAREZ, Klaudia; GALLEGO, Pablo; GÁNDARA, Fábio; RIVAS, Oscar. Nosotros, los indignados. Las voces comprometidas del \#15-M. Barcelona: Ed. Destinos, 2011.

ANDERSON, P. A rua e o poder. Estado de São Paulo, 03 nov. 2013. Cad Alias, p.E2. Entrevista realizada por Juliana Sayuri

BADIOU, Alain. El despertar de la historia. Madrid: Clave Editorial, 2012.

BOURGEOIS, Léon. Solidarité. L'ídée de solidarité \& ses conséquences sociales. Paris: Le Bord de L’ÉAU. 2008.

CACCIA-BAVA, Silvio. Le Monde Diplomatique, Paris, n.73, 13 ago. 2013. Disponível em: http:// www.diplomatique.org.br/editorial.phpedicao73.

CALLIGARIS, C. A pauta dos jovens sem pauta comum, Folha de São Paulo, 17 nov. 2011. p.E14.

CASTELLS, Manuel. A sociedade em rede. São Paulo: Paz e Terra, 1999 Zahar, 2013a.

Redes de indignação e esperança. São Paulo:

Redes de indignação e esperança. In: SEMINÁRIO

FRONTEIRAS DO PENSAMENTO, São Paulo, apud MATIAS,

A Alexandre. O ponto em comum entre a praça Taksim e aveni-

స da Paulista. Revista Galileu, 12 jun. 2013b, p.1-4.

$\therefore$ CARR, Nicholas. Os superficiais-o que a internet está fazendo com os nossos cérebros? São Paulo: Ediouro, 2011.

CHOMSKY, Noam. Ocсupy. New York: Penguin Books, 2012

COHN-BENDIT, Daniel. Violência em protesto reduz influencia, diz líder de Maio de 68’. Entrevista realizada por Fabio Brisolla. Folha de São Paulo, 06 nov. 2013. p.C7.

DANET, Nicolas; BARDEAU Frédéric. Anonymous: peuvent-ils changer le monde? Paris: FYP Editions, 2011 DEPUIS-DÉRI, Francis. Black Blocs. São Paulo: Ed.Veneta, 2014 DELLA PORTA, Donatella. O movimento por uma nova globalização. São Paulo: Loyola, 2007

DELLA PORTA, Donatella; TARROW, Sidney (Org.) Transnational protest and global activism. London Rowman\& Littlefield Publi, 2005.

GOHN, Maria da Glória. Sociologia dos movimentos sociais. 2.ed. São Paulo: Cortez Ed, 2014

Manifestações de junho de 2013 no Brasil e Praças dos Indignados no Mundo. Petrópolis: Vozes, 2014.

Após atos governo não tem interlocutores. Es- tado de São Paulo, 14 jul. 2013. Cad. Política Nacional, A14. Disponível em: www.portal do estadão.com.br.

Teorias dos movimentos sociais. Paradigmas clássicos e contemporâneos. 10.ed. São Paulo: Loyola Edições, 2012.

. Movimentos sociais e redes de mobilizações civis no Brasil Contemporâneo. 7.ed. Petrópolis: Vozes, 2013.

. Movimentos sociais e educação. 8.ed. São Paulo: Cortez, 2012.

Novas teorias dos movimentos sociais. 5.ed.São Paulo: Loyola, 2014

História dos movimentos e lutas sociais. 7.ed. São Paulo, 2012

HESSEL, Stéphane. Indignai-vos! 3.ed. Lisboa: Ed. Objectiva, 2011

HOLlOWAY, J. Cambiar el mundo sin tomar el poder. Madrid: El Viejo Topo, 2002.

HOLSTON, John. Cidadania insurgente. São Paulo: Companhia das Letras, 2013.

HONNETH, Axel. Luta por reconhecimento. A gramática moral dos conflitos sociais. São Paulo: Editora 34, 2003

JURIS, Jeffrey S. Violencia Representada e Imaginada Jóvenes activistas, el Black Bloc y los medios de comunicación en Génova In: FERRANDIZ, Francisco FEIXA, Carles (Ed.) Jóvenes sin tregua: culturas y politicas de la violencia. Barcelona: Anthropos, 2005. p.185-208.

LINERA, A. García Sociologia dos movimentos sociais. São Paulo: Boitempo, 2009.

LÖWY, Michel. Negatividade e utopia do movimento altermundialista. Lutas Sociais, São Paulo, PUC, n.19/ 20, p.32-38, jun./dez. 2008.

McDONALD, Kevin. Global movements. Action and culture. Oxford: Blackwell, 2006.

MOORE JR, Barrington. Injustiça: as bases sociais da obediencia e da revolta. São Paulo: Brasiliense, 1987

NEGRI, Antonio; Cocco, Giuseppe. Global: biopoder e luta em uma América Latina globalizada. São Paulo: Record, 2005.

NOGUEIRA, Marco Aurélio. As ruas e a democracia. Ensaios sobre o Brasil contemporâneo. São Paulo: Contraponto, 2013.

PLEYERS, Geoffrey; PLEYERS, Alter. Globalization. Becoming actors in the global age. Cambridge: Polity, 2010.

RANCIÉRE, Jacques. Políticas da escrita. São Paulo: Ed. 34, 1995

RHEINGOLD, H. SmartMobs: The next social revolution. Cambridge, MA: Perseus, 2002.

ROSENMANN, M.R. Los indignados. El resgate de la politica. Madri: Akal, 2012.

SEOANE, José; TADDEI, Emilio (Org.) Resistências mundiais. Petrópolis: Vozes, 2001.

SOLANO, Esther; ALCADIPANI, Rafael. Violência 'black bloc' visa chamar atencão de um Estado ausente. Folh de São Paulo, 17 out. 2013. C7.

SOLANO, Esther. Violência em atos ofusca movimentos pacíficos. Estado de São Paulo, 03 nov. 2013. p.A27. Entrevista citada por Bruno P Manso.

STRECKER, M. Occupy Wall Street e a web, Folha de São Paulo, 17 out. 2011. Mercado, B9.

TARROW, S. New Transnational activism. Cambridge: Cambridge Press, 2005.

TOURAINE, Alain. Un nouveau paradigme. Paris: Fayard, 2005 


\section{BRAZILIAN SOCIETY IN MOTION: the voices from the streets and their political echoes}

\section{Maria da Glória Gohn}

The aim of this article is to analyze both specificities and novelties in the June 2013 demonstrations in Brazil by means of a few key questions, namely: what their composition was, what identities, belonging, values, and ideologies they had; what they demanded, how they were articulated both internally and on an international level; what relations they had with the State, parties, and other social movements, how violence emerges in the demonstrations, what concept of democracy the activists had, how the idea of reforms was guided, etc. One central question is posited: why did a large mass of the population join the protests in June 2013? Initially, we reconstruct the demonstrations' initial moments, particularly in São Paulo, as well as subsequent moments, according to their impacts on society and politics. Data sources are from systematized archives obtained through several media, interviews, public opinion surveys, and recent publications.

Keywords: Demonstrations, Protests, Social Movements, Civil society mobilization, sociopolitical activism.

\section{LA SOCIÉTÉ BRÉSILIENNE EN MOUVEMENT: les voix de la rue et leurs échos politiques et sociaux}

\author{
Maria da Glória Gohn
}

Lobjectif du texte est d'analyser les aspects spécifiques et nouveaux des manifestations de juin 2013 au Brésil par le biais de quelques questionsclés, à savoir: comment étaient-elles composées, quelles étaient leurs identités, leur appartenance, quelles valeurs et quelles idéologies avaient-elles; quelles étaient leurs revendications, comment étaient-elles articulées au niveau national et international; quel rapport avaient-elles avec l'état, les partis et d'autres mouvements sociaux; comment la violence surgit-elle au sein des manifestations; quelle est la conception de démocratie des activistes; comment l'idée de réforme a-t-elle été présentée, etc. Une question centrale est posée: pourquoi un tel nombre de personnes a-t-il adhéré aux protestations de juin 2013? Tout d'abord, c'est une reconstitution des moments qui sont à l'origine des manifestations qui est faite, tout spécialement à São Paulo, ensuite elles sont analysés en fonction de leurs impacts dans la société et dans la politique. Les données proviennent d'archives systématisées via différents médias, interviews, enquêtes d'opinion publique et de publications récentes.

Mots-Clés: Manifestations. Protestations. Mouvements sociaux. Mobilisation de la société civile. Activisme sociopolitique.

Maria da Glória Gohn - Doutora em Ciência Política. Pós-Doutorado pela New School University, N. York. Bolsista I do Conselho Nacional de Desenvolvimento Científico e Tecnológico (CNPQ). Professor titular da Faculdade de Educação da Universidade Estadual de Campinas (UNICAMP). Membro do board de coordenação do Comitê Social Movements and Social Classes da Associação Internacional de Sociologia (ISA). Parecerista ad hoc da avaliação de periódicos SciELO. Parecerista do CNPq, da Fundação de Amparo à Pesquisa do Estado de São Paulo (FAPESP) e da Coordenação de Aperfeiçoamento de Pessoal de Nível Superior (CAPES). Tem experiência na área de Sociologia, Educação e Políticas Sociais, atuando principalmente nos seguintes temas: movimentos sociais, participação social, educação não formal, associativismo e cidadania. Publicou 18 livros de autoria individual e inúmeros capítulos em coletâneas. Dentre seus livros, destacam-se: Sociologia dos movimentos sociais (Cortez, 2014, 2a ed.); Historia dos movimentos e lutas sociais (Loyola, 2013, 8a ed.); Movimentos sociais e redes de mobilizações civis no Brasil contemporâneo (Vozes, 2013, 7a ed.); Movimentos Sociais e Educação (Cortez, 2012, 8a ed.); Teorias dos movimentos sociais (Loyola, 2012, 10a ed.). 
